\title{
Modeling and Scaling Up of Industrial Spray Dryers: A Review
}

\author{
Ireneusz ZBICINSKI \\ Faculty of Process and Environmental Engineering, Lodz University of Technology, 213 Wolczanska Str., \\ Lodz 90-924, Poland
}

Keywords: Industrial Spray Towers, Hydrodynamics, Agglomeration, Drying Kinetics, Wall Deposition, Scaling Up

\begin{abstract}
The paper presents a review of research works, experiments and simulations on spray drying in the industrial scale. The research area in the industrial spray drying process covers control of powder properties (bulk density, morphology), particles agglomeration (final PSD), residence time, wall deposition and safety of the process and the product. Limited number of literature references on spray drying in the industrial scale is due to high costs of running experiments and validation of theoretical models. Recent works on hydrodynamics in spray towers showed transient, oscillating, 3D flow of dispersed and gas phase which results from construction of inlet and exhaust ducts and swirl decay due to wall roughness (deposits). Applications of the most advanced and accurate empirical methods to calculate spray drying kinetics in industrial scale; the Characteristic Drying Curves (CDC) and the Reaction Engineering Approach (REA) were presented. The main obstacles denying confident scaling up of the spray drying process; lack of dynamic similarity between small and large units, gas turbulence modelling, determination of drying kinetics and neglecting of agglomeration process are highlighted. Methods of modelling of the agglomeration process in spray drying (transition functions, full scale agglomeration) are described. Examples of modelling and measurements of hydrodynamics, wall deposition, agglomeration process and drying kinetics in the industrial towers are presented and discussed.
\end{abstract}

\section{Introduction}

Idea of spray drying was presented for the first time in 1865 by C. A. La Mont, (after Masters, 1985), whereas the first application is dated on 1872, when Samuel Percy registered the first patent for production of the milk powder, (Percy, 1872). At the beginning of the XX century, drying concept based on feed atomization was called "spray concentration". Currently used terminology "spray drying" was introduced together with wider applications of this method of drying in food and chemical industry.

140 years of research resulted in development of different spray drying techniques and numerous applications in the industry, especially of co-current spray drying system.

Counter-current systems, patented already in 1888 (J. H. Bassler, for drying of juice, milk, etc., after Masters, 1985) are sparsely encountered in the industry and are mainly applied for production of detergents. Counter-current spray dryers in relation to co-current systems offer higher throughput and heat efficiency, less dust, control of product bulk density, multilevel atomization and lower production costs, Rahse and Dicoi (2001).

Modelling of spray drying process is still one of the biggest challenges among all drying technologies; Oakley (1994), pointed out that dimensional analysis cannot be applied for modelling of spray dryers due to lack of dy-

Received on November 28, 2016; accepted on February 15, 2017 DOI: $10.1252 /$ jcej.16we350

Presented at the 20th International Drying Symposium (IDS 2016), Gifu, August 2016

Correspondence concerning this article should be addressed to I. Zbicinski (E-mail address: ireneusz.zbicinski@p.lodz.pl). namic similarity between small and large chambers. Masters (1994), claims that for confident scaling up of spray drying process the new design can be scaled-up up to $20 \%$ in relation capacity of a previous design.

CFD technique which emerged in the 80 -ties and is still developed, brought new openings for modelling of 3D, transient flow in spray drying including hindered drying, agglomeration, flow stability and wall deposition, Fletcher et al. (2006).

\section{Hydrodynamics in Industrial Towers}

At the end of the 90ties of the last century, significant development of measuring techniques was observed. The companies like Dantec, TSI or Malvern introduced to the market sensors for non-invasive, in situ measurements of PSD and velocity of continuous and disperse phase which gave an impulse for deeper experimental analysis of spray drying process.

Bayly et al. (2004) applied LDV (Laser Doppler Velocimetry) to determine axial and tangential air velocity in $8 \mathrm{~m}$ tall and $5 \mathrm{~m}$ in diameter counter-current spray dryer (no drying process). Experimentally determined velocity profiles were used to validate CFD model of the gas flow in the dryer. The authors applied Reynold Stress Model to predict flow turbulence. The model showed good agreement with experimental data and can be used for scaling up of industrial scale towers.

Langrish and Fletcher (2003) reported works in the Australian dairy industry in $10 \mathrm{~m}$ in diameter dryer. The authors determined oscillating, transient, three dimensional flow patterns of gas and dispersed phase.

Gabites at al. (2010) analysed theoretically and experi- 


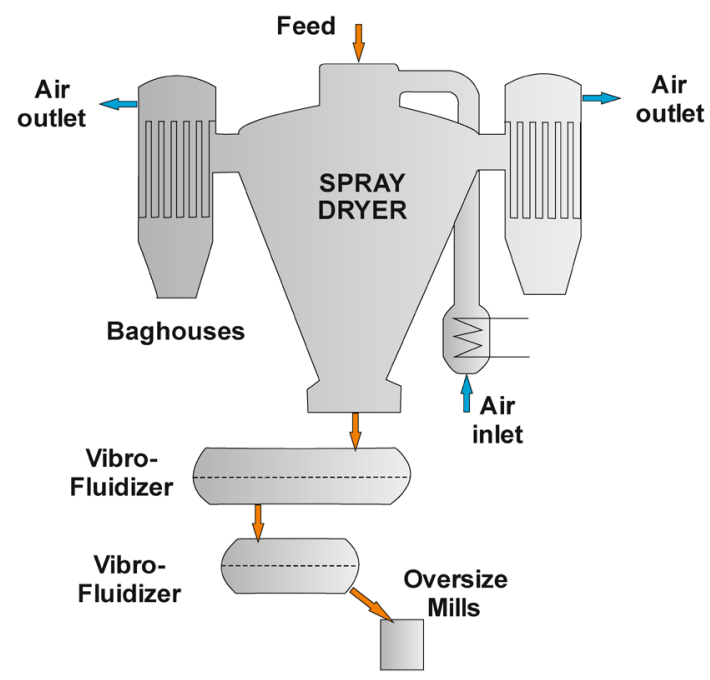

Fig. 1 Industrial milk powder spray tower with internal fluid bed, Gabites at al. (2010)

mentally air flow patterns in an industrial milk powder spray tower with internal fluid bed in isothermal conditions (no atomised liquid droplets), Figure 1. The authors detected oscillations and precession of the main air jet around the central axis with no apparent distinct frequency. They observed also fluctuations in size of the recirculation zones between the main jet and the chamber walls. The simulations were validated in simple experiments using the telltale rig $(3 \mathrm{~m}$ high stainless steel pole with fabric tufts placed at $200 \mathrm{~mm}$ intervals) to measure the period of oscillation of the main air jet. Woo et al. (2012) used similar experimental technique (cotton turf and hotwire measurements) to describe the highly swirl flow in a small spray dryer.

The results of the simulations allowed the authors to make suggestions important for industrial practice regarding construction and operation of the tower; location of outlet ducts (near the top rather than the bottom of the dryer) and keeping constant pressure conditions downstream to the dust collector.

Extensive experiments and simulations of flow in counter current spray towers for detergent manufacture has been carried out recently by Francia et al. (2015a, 2015b). The authors studied airflow parameters (air velocity and turbulence) in isothermal conditions (no drying process) in swirl counter-current industrial tower (Figure 2) using a sonic anemometer. They confirmed that the flow pattern in the tall towers depends mainly on the design of hot air inlet construction, Wawrzyniak et al. (2012a). The authors identified field asymmetries owned to the design of inlet and exhaust ducts, anisotropic field and the decay of the turbulence kinetic energy, the precession and oscillations of the vortex core and strong effect of wall friction on swirl decay.

The most important finding of the work is proving that the swirl intensity decays exponentially during the flow in the dryer. As the industrial spray towers have high wall roughness due the presence of deposits, neglecting the role of wall deposits (e.g., in CFD models) might cause an over

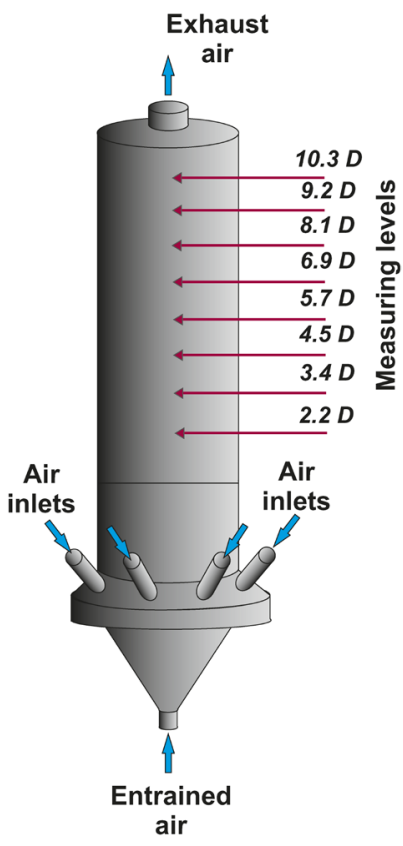

Fig. 2 Measurements levels in swirl counter-current industrial tower, Francia et al. (2015a)

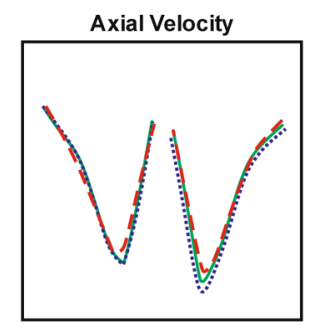

Tangential Velocity
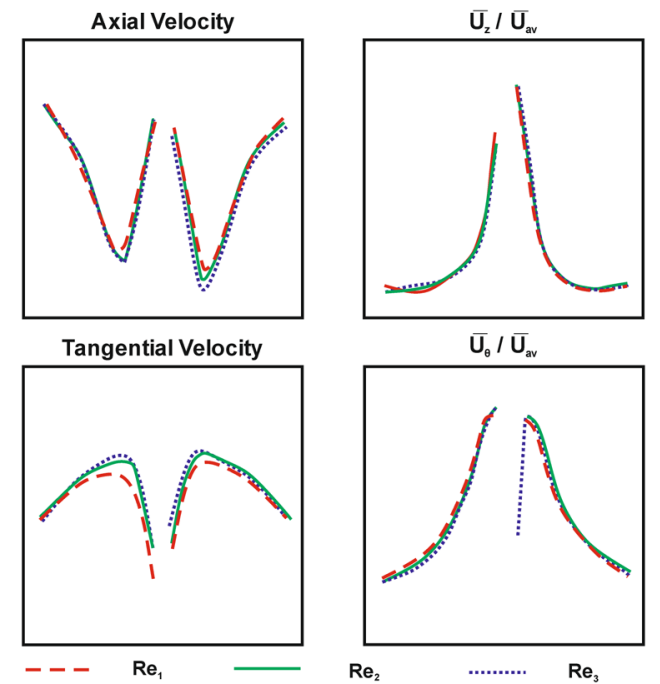

$\overline{\mathrm{U}_{9}} / \overline{\mathrm{U}}_{\mathrm{a}}$

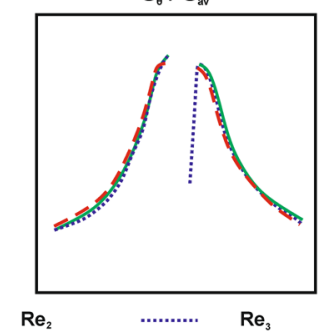

Fig. 3 Axial velocity $U_{\mathrm{ax}}$ and tangential velocity $U_{\tan }$ at the same distance from the air inlet for different Re numbers, Francia et al. (2015a)

prediction of the tangential velocity around $30-40 \%$. Moreover, erroneous prediction of the flow pattern in the tower affects calculations of the concentration of particles near the wall, the rates of deposition and erosion and particle residence time. Examples of measured axial and tangential velocities for different Re numbers are shown in Figure 3. No effect of $R e$ on axial and tangential velocity in the tower was found in the range of $R e=10 \times 10^{5}-2.2 \times 10^{5}$. Characteristic profiles of all normalized velocities (in relation to average air velocity, $U_{\mathrm{av}}$ ) are in agreement with the standard pattern of swirling flows.

Similar phenomenon was reported by Fletcher et al. 


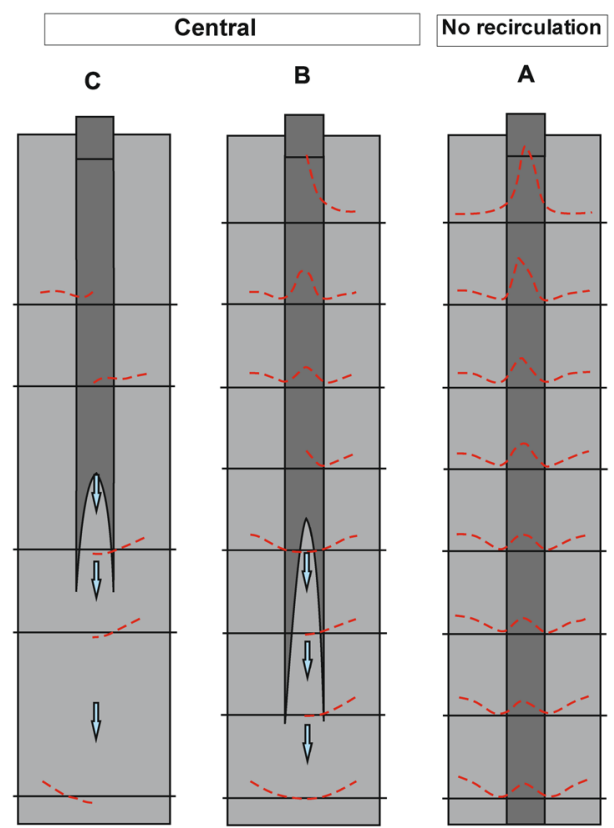

Fig. 4 Flow regimes in counter-current swirl dryers. Shadowed areas delimit the upwards jet and arrows the areas of reverse flow. Plots to scale of axial velocity $U_{z}$ (top) and tangential velocity $U_{\tan }$ (bottom) for the cylindrical chamber, Francia et al. (2015b)
(2006) for gas flow simulations in commercial spray dryer $10 \mathrm{~m}$ in diameter and $30 \mathrm{~m}$ in height. A precession of the jet coming close to the walls promoting particles to hit the wall, with frequency of around $1 \mathrm{~Hz}$ was observed.

Francia et al. (2015b) investigated the effect of wall friction on flow regimes and the structure of the vortex flow in three counter-current units of varying scale and design. For the industrial dryer the authors analyzed air flow pattern for three different amount of the deposit on the wall; clean walls, small deposition (e.g., for short term production), heavy deposition (long term production, no automatic cleaning)

The following flow regimes resulting from different wall friction; (1) no recirculation, (2) central recirculation and (3) annular recirculation were identified, Figure 4. The authors concluded that neglecting the deposits and assuming smooth walls would result in "over-prediction of swirl velocity up to $40 \div 186 \%$, under-prediction of turbulent kinetic energy up to $67 \div 85 \%$ and failure to recognize recirculation areas".

Table 1 shows summary of works on hydrodynamics in industrial spray dryers.

Table 1 Research works on hydrodynamics in industrial spray dryers

\begin{tabular}{|c|c|c|c|c|}
\hline No. & Authors & Dryer & Method & Findings \\
\hline 1. & $\begin{array}{l}\text { Straatsma et al. } \\
\text { (1999) }\end{array}$ & $\begin{array}{l}\text { Two industrial cone } \\
\text { type spray dryers } \\
l=14 \mathrm{~m}, d=9.4 \mathrm{~m} \\
l=17 \mathrm{~m}, d=10 \mathrm{~m}\end{array}$ & $\begin{array}{l}\text { 2D steady state } \\
\text { simulations }\end{array}$ & $\begin{array}{l}\text { The flow field in the chamber characterized by fast flowing core with } \\
\text { large recirculation zones between the central jet and the walls }\end{array}$ \\
\hline 2. & Harvie et al. (2002) & $l=9.7 \mathrm{~m}, d=2.2 \mathrm{~m}$ & $\begin{array}{l}\text { Steady state } \\
\text { simulations }\end{array}$ & $\begin{array}{l}\text { Central downward jet extended the length of most of the chamber, } \\
\text { recirculation zones existed between the jet and dryer walls in the } \\
\text { upper part of the chamber. Negligible effect of particles presence on } \\
\text { gas velocities. No transient flow behavior }\end{array}$ \\
\hline 3 & $\begin{array}{l}\text { Langrish and } \\
\text { Fletcher (2003) }\end{array}$ & $\begin{array}{l}\text { Dairy industry } \\
d=10 \mathrm{~m}\end{array}$ & $\begin{array}{l}\mathrm{CFD} \\
\text { simulations }\end{array}$ & Transient, 3D flow patterns of gas and dispersed phase \\
\hline 4 & Bayly et al. (2004) & $\begin{array}{l}l=8 \mathrm{~m}, d=5 \mathrm{~m} \text { Con- } \\
\text { current spray dryer }\end{array}$ & $\begin{array}{l}\text { LDV, no } \\
\text { drying process }\end{array}$ & Axial and tangential air velocity for validation of CFD model \\
\hline 5 & $\begin{array}{l}\text { Fletcher et al. } \\
\quad(2006)\end{array}$ & $l=30 \mathrm{~m}, d=10 \mathrm{~m}$ & Simulations & $\begin{array}{l}\text { A precession of the jet coming close to the walls promoting particles } \\
\text { to hit the wall, with frequency of } 1 \mathrm{~Hz}\end{array}$ \\
\hline 6 & $\begin{array}{l}\text { Gabites at al. } \\
\quad(2010)\end{array}$ & $\begin{array}{l}\text { Cone spray tower } \\
\text { with internal } \\
\text { fluid bed, } l=22 \\
d=18 \div 5 \mathrm{~m}\end{array}$ & $\begin{array}{l}3 \mathrm{~m} \text { high } \\
\text { telltale rig, } \\
\text { Figure 1, no } \\
\text { drying process }\end{array}$ & $\begin{array}{l}\text { Oscillations and precession of the main air jet around the central } \\
\text { axis with no apparent distinct frequency, fluctuations in size of the } \\
\text { recirculation zones between the main jet and the chamber walls. }\end{array}$ \\
\hline 7 & $\begin{array}{l}\text { Francia et al. } \\
\quad(2015 a)\end{array}$ & $\begin{array}{l}\text { Swirl con-current } \\
\text { industrial tower, } \\
l / d=10.58\end{array}$ & $\begin{array}{l}\text { Sonic } \\
\text { anemometer, } \\
\text { Figure } 2 \text {, } \\
\text { no drying } \\
\text { process }\end{array}$ & $\begin{array}{l}\text { Flow asymmetries owned to the design of inlet and exhaust ducts, } \\
\text { the decay of the turbulence kinetic energy, the precession and oscil- } \\
\text { lations of the vortex core. Swirl intensity decays exponentially due to } \\
\text { high wall roughness produced by the deposits, neglecting the role of } \\
\text { wall deposits might cause an over prediction of the tangential veloc- } \\
\text { ity around 30-40\%. }\end{array}$ \\
\hline 8 & $\begin{array}{l}\text { Francia et al. } \\
\quad(2015 b)\end{array}$ & $\begin{array}{l}\text { Three counter- } \\
\text { current units of } \\
\text { varying scale and } \\
\text { design, } l / d=10.58, \\
l / d=2.97, l / d=2.87\end{array}$ & $\begin{array}{l}\text { Sonic } \\
\text { anemometer, } \\
\text { no drying process }\end{array}$ & $\begin{array}{l}\text { Strong effect of wall friction on flow regimes and the structure of the } \\
\text { vortex flow, } 3 \text { regimes: clean walls, small deposition, heavy deposi- } \\
\text { tion. Neglecting the deposits results in "over-prediction of swirl ve- } \\
\text { locity up to } 40 \div 186 \% \text {, under-prediction of turbulent kinetic energy } \\
\text { loss up to } 67 \div 85 \% \text { and failure to recognize recirculation areas" }\end{array}$ \\
\hline 9 & $\begin{array}{l}\text { Wawrzyniak et al. } \\
\qquad(2012 \mathrm{a})\end{array}$ & $\begin{array}{l}l=37, d=6, \text { con-cur- } \\
\text { rent, no swirl flow }\end{array}$ & $\begin{array}{l}\text { Anemometer, } \\
\text { no drying process }\end{array}$ & High flow instability \\
\hline
\end{tabular}




\section{Wall Deposition}

Wall deposition is a serious and undesirable problem in industrial spray towers. To predict if the particles stick and deposit on the wall or rebound from the wall, moisture content and temperature of the particles must be known. Fletcher et al. (2006) calculated wall deposition rate along the dryer length the dryer for different atomization parameters, Figure 5.

Figure 5 shows that droplets mainly stick to the walls in the upper main chamber, the lower main chamber and at the base of the bustle as in these regions the flow field streamlines are tightly curved and the particles traversing the streamlines impact with the walls.

Gianfrancesco et al. (2010) elaborated CFD model to simulate the spray drying of maltodextrin DE12 and DE21 in a pilot co-current spray dryer to control material sickness. They estimated zones and operating conditions for which particles could be sticky inside the chamber on the basis of the evolution of particle temperature, water content and glass transition temperatures. Maltodextrin DE12 was quickly dried reaching a stable non sticky state below glass transition temperatures $T_{\mathrm{g}}$, while maltodextrin DE21 with

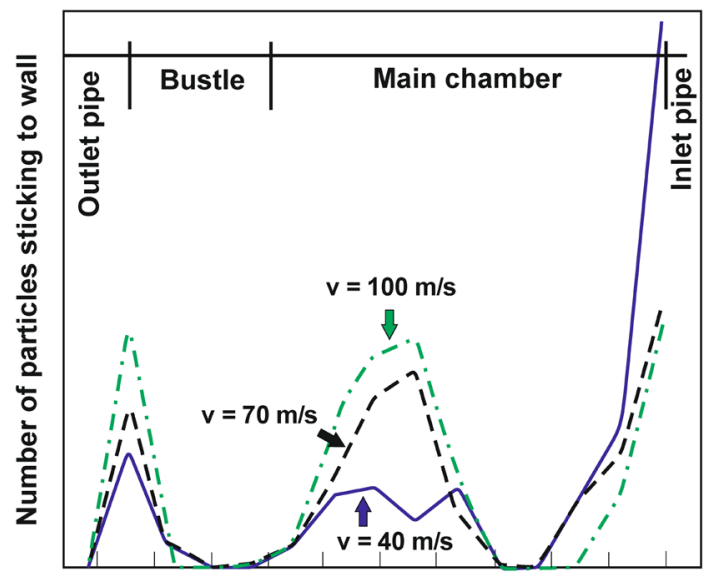

Height of spray drier [m]

Fig. 5 Wall deposition versus elevation within the dryer for different initial particle velocities, Fletcher et al. (2006)

\section{Calculated sticky zone}

Sticky zone considering $T_{p}=T_{w b}$
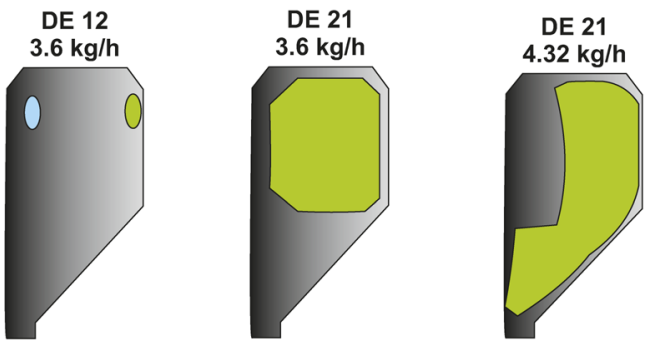

Fig. 6 Calculated sticky zones from simulation of spray drying of a maltodextrin DE12 and DE21 solution for different liquid flowrates, Gianfrancesco et al. (2010) lower $T_{\mathrm{g}}$ showed a sticky behavior in a wider area of the chamber, Figure 6.

The authors validated the predicted sticky conditions by powder insertion at different positions in the dryer for development of agglomerates.

Ullum et al. (2010), developed a CFD model to predict wall deposition in concurrent $4 \mathrm{~m}$ tall and $2 \mathrm{~m}$ in diameter spray dryer. Drying kinetics was determined from acoustic levitator experiments (Drying Kinetics Analyzer, DKA, Denmark) and from the standard Ranz-Marshall model. Both methods were implemented in the CFD code and the results compared with full-scale tests of drying of maltodextrin DE18. Figure 7 shows significant difference in prediction of particle humidity $X_{\mathrm{p}}$ and particle temperature $T_{\mathrm{p}}$ vs time for both methods.

Time to reach equilibrium in the DKA experiments was more than three times longer $\left(X_{\mathrm{p}}=\sim 0.1\right.$ at $\left.450 \mathrm{~s} / \mathrm{mm}^{2}\right)$ than for the Ranz-Marshall model, $X_{\mathrm{p}}=0$ at $150 \mathrm{~s} / \mathrm{mm}^{2}$, see Figure 7. The explanation might be the smaller size of particles in spray dryer than in the levitator (500-700 microns) which results in longer drying time in the experimental setup. The authors calculated particle deposition fluxes with temperatures above glass transition temperature. Figure $\mathbf{8}$ shows that for the DKA method, the rubbery product depositions was 70\%, no deposition (around 1.2\%) was observed for the Ranz-Marshall model due to the low water content when the particles collide with the chamber walls.

The authors claim that DKA model agreed well with the experiment regarding location of the region of maximum
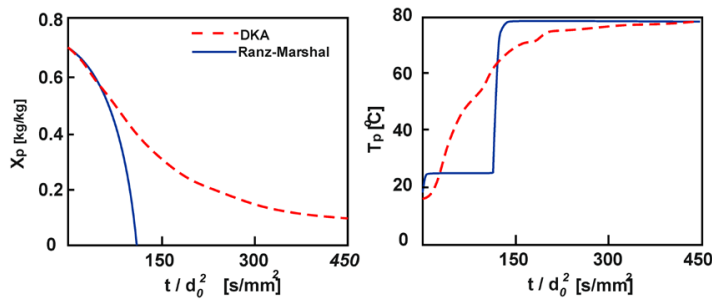

Fig. 7 Modeled particle moisture content $X_{\mathrm{p}}[\mathrm{kg} / \mathrm{kg}]$ and particle temperature $T_{\mathrm{p}}$ vs. scaled time at gas temperature for RanzMarshal model and DKA levitator experiments, Ullum et al. (2010)

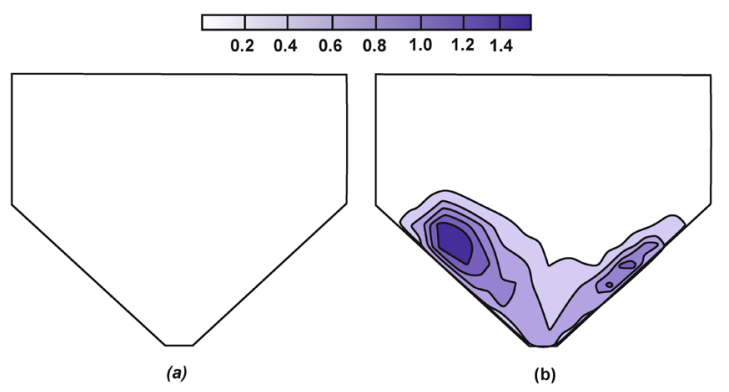

Fig. 8 Contours of particle deposition (at temperatures above glass transition temperature) on chamber cylinder and cone for the Ranz-Marshall model (a) and the DKA model (b), Ullum et al. (2010) 
rubbery deposits.

Birchal et al. (2006) estimated particle deposition on the dryer wall during drying of the whole milk suspension. They applied population balance model to calculate drying kinetics and 3D CFD model with stochastic tracing of the particle. The authors suggest that particles with high moisture content at low temperatures adhere more effectively to walls (as it follows from milk powder stick point diagram). On the basis of calculated particle trajectories they estimated that $46 \%$ of the particles hit the cylinder walls whereas only $24 \%$ will hit the conical dryer walls. To reduce wall deposit, the dryer chamber should be well insulated to increase temperature of the particles near the wall.

Jin and Chen (2010) developed particle deposition model for industrial spray dryer (capacity $9 \mathrm{t} / \mathrm{h}$ of milk powder, $15 \mathrm{~m}$ height, $8 \mathrm{~m}$ in diameter). The model calculates the particle deposition rate as a function of particle diameter, temperature, moisture content, velocity and air humidity. Three classes of particles were defined; surface tension-dominated, viscous forces dominated and dry particles, Orme (1997). Dry particles could return to the chamber after hitting the wall. The dryer wall was considered as clean at the beginning of the operation.

The results of the calculations Figure 9(a) showed stabile deposition flux rate after $80 \mathrm{~s}$. After about $200 \mathrm{~s}$, the deposition, removal, and net deposition flux rates at the conical

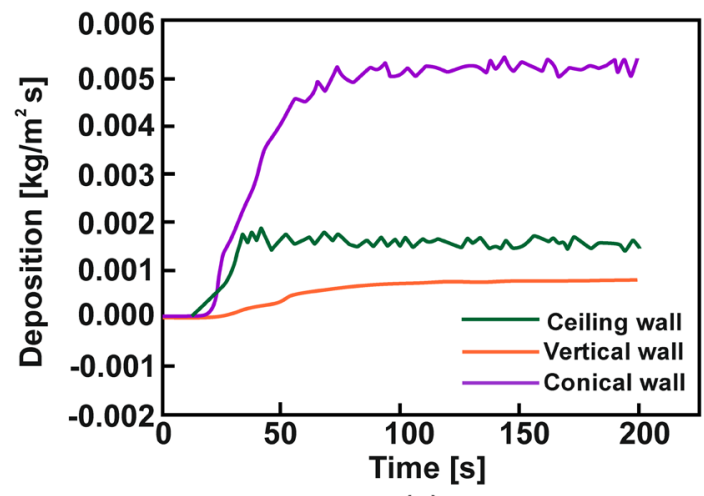

(a)

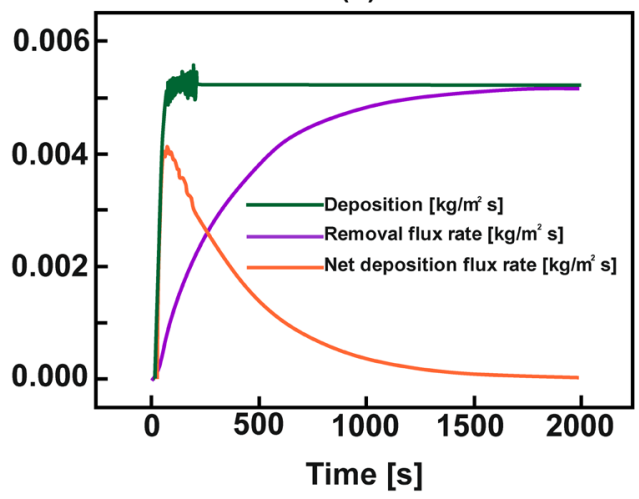

(b)

Fig. 9 An average deposition at the walls: (a) transient deposition flux rate on ceiling wall, vertical wall, and conical wall and (b) deposition flux rate, removal flux rate, and net deposition flux rate at the conical wall, Jin and Chen (2010) wall achieved the balance between the deposition and reentrainment, Figure 9(b).

The authors compared simulation results with the experimental data to find which wall boundary conditions; escaping wall or reflecting wall, offers better predictions of wall deposition rate. The comparison showed that reflecting wall boundary conditions describe more precisely the real physics of the industrial-scale spray dryer and deliver more accurate particle flow pattern and wall deposition rate whereas escaping wall boundary conditions overpredicted the deposition rate.

\section{Drying Kinetics}

Correct determination of drying kinetics is condicio sin qua non for confident scaling up of spray drying process, both in small and in industrial scale. In the literature, drying kinetics models can be divided into three groups, Langrish (2009): deterministic models, empirical models based on the Characteristic Drying Curves (CDC) and the Reaction Engineering Approach (REA).

Deterministic models (diffusion models, e.g., Liou and Bruin (1982), Mezhericher et al. (2007), Chen (2004) calculate resistance in moisture transport inside the particle. This method requires application of moving boundary conditions which significantly increase calculation time.

The Reaction Engineering Approach assumes that evaporation requires the activation process to overcome an energy barrier. The basic concept of REA was developed by Chen and Xie (1997), Chen (2008).

The last groups of droplet drying models are based on the characteristic drying curve (CDC) concept. In CDC it is assumed that, for each average moisture content, exists a corresponding specific relative drying rate.

Woo et al. (2008) compared with experiments droplet drying of sugar solutions using CDC and REA techniques and showed good accuracy of both methods.

The authors observed also generation of particle clouds for particles $224-285 \mu \mathrm{m}$ with frequency of $0.5-1 \mathrm{~Hz}$ near the conical wall, transported upwards and dispersed into the air stream. These sizes of particles have the longest residence time.

Taylor (2000) compared residence time in $12 \mathrm{~m}$ in height and $2.25 \mathrm{~m}$ in diameter co- and counter-current industrial spray tower. Particle residence time was determined with a marker injected to the spray stream. The author found that the average residence time in co-current spray drying was shorter than in counter-current process. Additionally, the product after counter-current spray drying had bigger bulk density and bigger average particle diameter due to intensive agglomeration.

The advantage of CDC and REA methods is easy implementation in complex CFD models and quick simulation of droplet drying process, Jin and Chen (2009). A serious limitation of both methods is the necessity of experimental determination of the drying curve for tested material in order to fit parameters of the two models. 


\section{Particle Agglomeration}

Intensive agglomeration is observed in industrial spray towers which results in a significant increase of a particle diameter. The rate of agglomeration and size of the agglomerates, in addition to the physicochemical properties of the atomized solution, are affected by the spray drying process parameters, geometry of the tower, the method of phase contact (co-current, counter-current or mixed) and method of feed atomization.

Changes of particle size have a significant impact on the process of drying and must be taken into account when scaling up spray drying process, Fletcher et al. (2006). Dropletdroplet interactions during the spray drying were analyzed by Mezhericher et al. (2007) who confirmed that droplet collisions influenced significantly the air temperature and humidity patterns in the dryer.

Huntington (2004) concluded that in counter-current spray drying, the agglomeration controls the final product properties. The author stressed the need to determine mechanism of agglomeration process which might take place between droplets, droplet and partially dried particles and between particles.

In any case, to model agglomeration process in spray drying the functions describing transition from the initial to the final PSD must be determined.

In the literature we can find several methods for modelling of the agglomeration process: direct modelling, Hirt and Nichols (1981), Li and Fritsching (2012), stochastic models, Ho and Sommerfeld (2002), Kim et al. (2009), Taskiran and Ergeneman (2014) and particle populations balance models, Nijdam et al. (2004), Tsotsas and Mujumdar (2007).

None of the particles agglomeration models have been fully validated due to difficulties of carrying out measurements in the industrial scale and lack of data on material properties (e.g., glass transition temperature or stickiness),

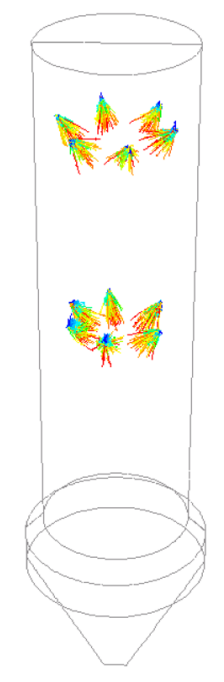

Fig. 10 Schematic of the industrial tower with dispersed phase injection regions, Wawrzyniak et al. (2012a, 2012b) tower geometry, operating parameters which, in many cases are inaccessible or confidential.

In this paper two methods for modeling of agglomeration process in industrial spray towers are presented, (1) simple method based on arbitrary selected transition functions and (2) full scale agglomeration models based on modification of stochastic model which takes into account collisions of droplets, wet and dry particles and coupling with heat, mass and momentum transfer.

Presented here CFD and agglomeration models were verified on the basis of measurements in the industrial spray tower for washing powder, Wawrzyniak et al. (2012b).

The industrial tower shown schematically in Figure 10 was $37 \mathrm{~m}$ height and $6 \mathrm{~m}$ in diameter. A system of 720 bag filters to purify the outlet air was installed at the top of the tower. The walls of the tower were well insulated with a layer of mineral wool.

Slurry was sprayed by systems of 12 nozzles located on two levels of $18 \mathrm{~m}$ and at $10 \mathrm{~m}$ from the hot air inlets. The spray angle of the nozzles was $65^{\circ}$. The initial droplet distribution ranged from 20 to $600 \mu \mathrm{m}$. Final average particle diameter was 770 microns in the product.

Both agglomeration models $(1,2)$ were implemented in CFD model of spray drying of washing powder in the tower. Correctness of the CFD model (as well as the agglomeration models) was estimated on the basis of comparison of experimentally determined and calculated air temperature and velocity distributions in the spray tower. The gas temperature measurements were made using a microseparator which construction was adapted from Kievet and Kerkhof (1996) to carry out temperature measurements on an industrial scale, Figure 11. Microseparator separates particles from air delivering decontaminated air to the hidden thermocouples for accurate gas temperature measurements.

Figures 12 and 13 show experimental set up for mi-

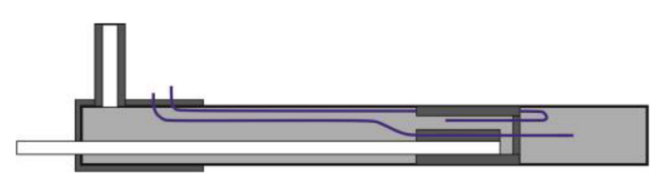

Fig. 11 Schematic of the microseparator used in industrial measurements; contaminated air inlet from the right hand side

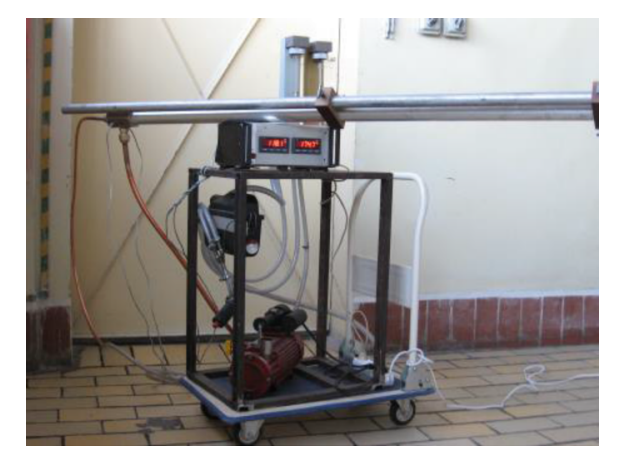

Fig. 12 Experimental set up for microseparator measurements in the industrial tower 
croseparator gas temperature measurements during the industrial spray tower operation and particles build-up on the outer tube after the measurements.

In the transition functions method (1) of calculations of the agglomeration process of dispersed phase in the drying tower only the initial PSD, density of the slurry and final density of the product must be known, Jaskulski (2015). Logistic function was arbitrally assumed to describe agglomeration process (Eqs. (1) and (2)).

Particle diameter $d_{\mathrm{p}}$ of fraction " $i$ " was determined from Eq. (1) where loss of particle mass $m_{\mathrm{p}}$ was calculated from evaporation model whereas particle density from logistic function (Eq. 2), Figure 14.

$$
d_{p, i}=\sqrt[3]{\frac{6 \cdot m_{p, i}}{\pi \cdot \rho_{p, i}}}, \quad i \in\langle 1, n\rangle
$$

where $n$ is number of particle fractions.

$$
\rho_{p, i}=\rho_{\text {fin }}+\frac{\rho_{\text {init }}-\rho_{\text {fin }}}{1+(a \cdot t)^{n}}
$$

where a and $\mathrm{n}$ are constants characteristic for given spray drying process, $\rho_{\text {init }}$ is the initial density of the slurry and $\rho_{\text {fin }}$ is the tap density of the powder, $t$ is time.

The shape of the logistic function depends on the time of agglomeration which was determined from preliminary

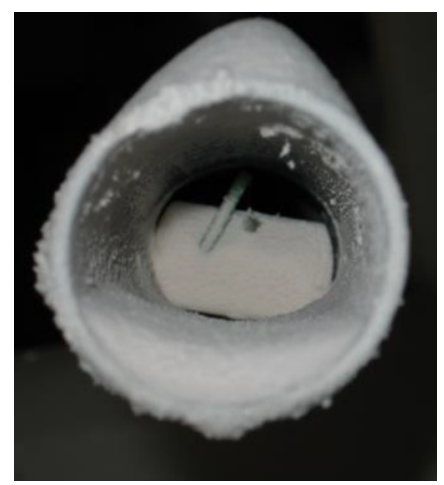

Fig. 13 Particles build-up on the outer tube of the microseparator

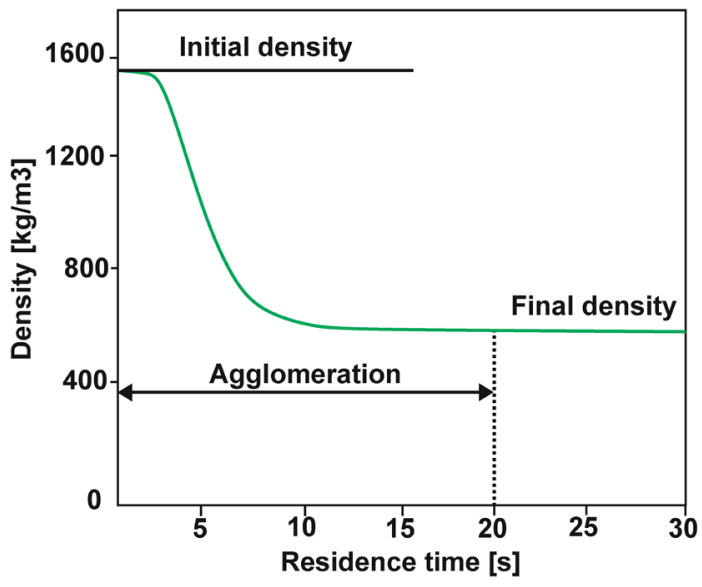

Fig. 14 Changes of particle density in the drying chamber
CFD calculations. Residence time of particles in the spray drying tower was estimated to be in the range from 20 to 60 s. On the basis of CFD calculations, an average agglomeration time during which the initial PSD turned into the final PSD for each fraction in the tower, was set to $20 \mathrm{~s}$.

Constants $a=0.2$ and exponent $n=4$ were determined from the CFD calculations of particle trajectories. For the analyzed product, detergent, initial density was equal to $\rho_{\text {init }}=1,550 \mathrm{~kg} / \mathrm{m}^{3}$, final $\rho_{\text {fin }}=550 \mathrm{~kg} / \mathrm{m}^{3}$.

Comparison of the theoretical and experimental results shows good match which proves correctness of applied simple methodology to predict final PSD of the product, Figure 15.

The second approach to model agglomeration in spray drying reflects the mechanism of the agglomeration process,
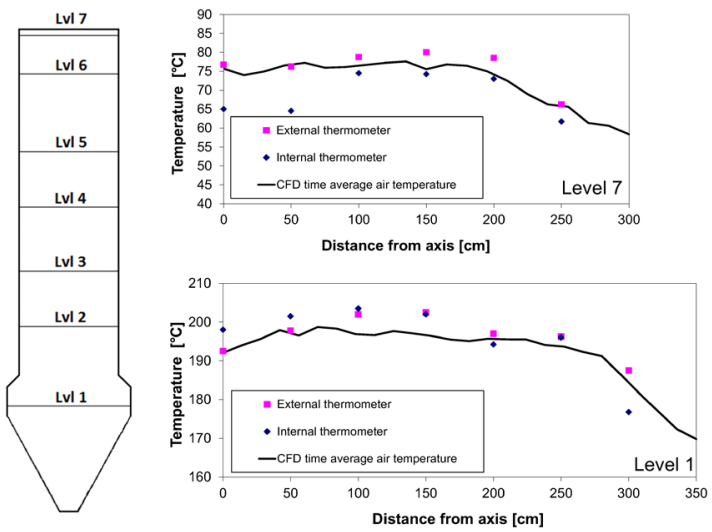

Fig. 15 Measured and calculated, time averaged radial air temperature profiles on two tower levels, Wawrzyniak et al. (2017)
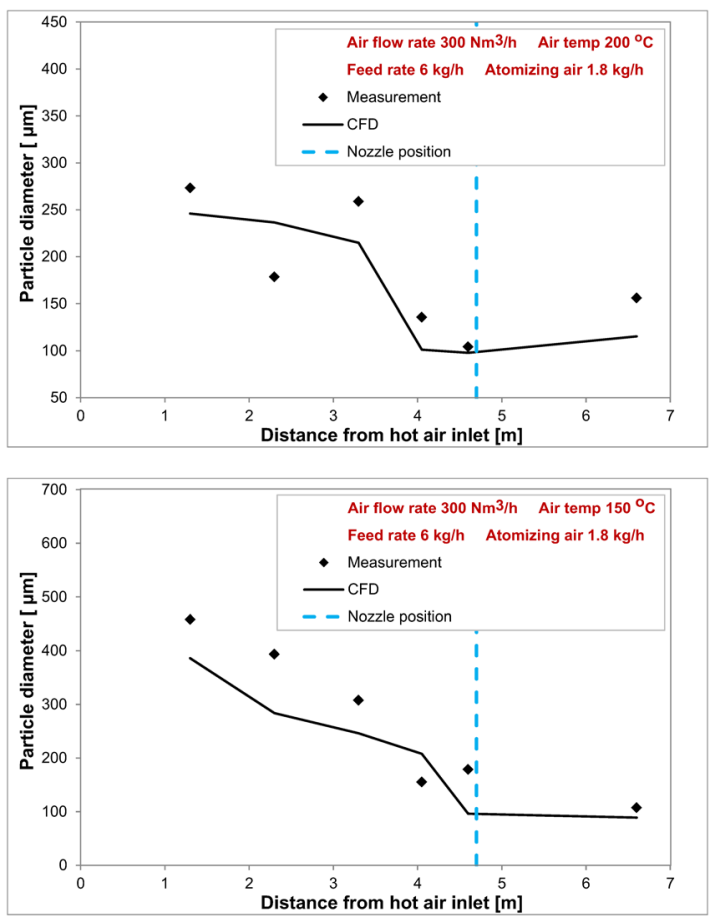

Fig. 16 Changes in mean particle diameter along dryer height with nozzle at $4.7 \mathrm{~m}$ from air inlets, Piatkowski (2011) 


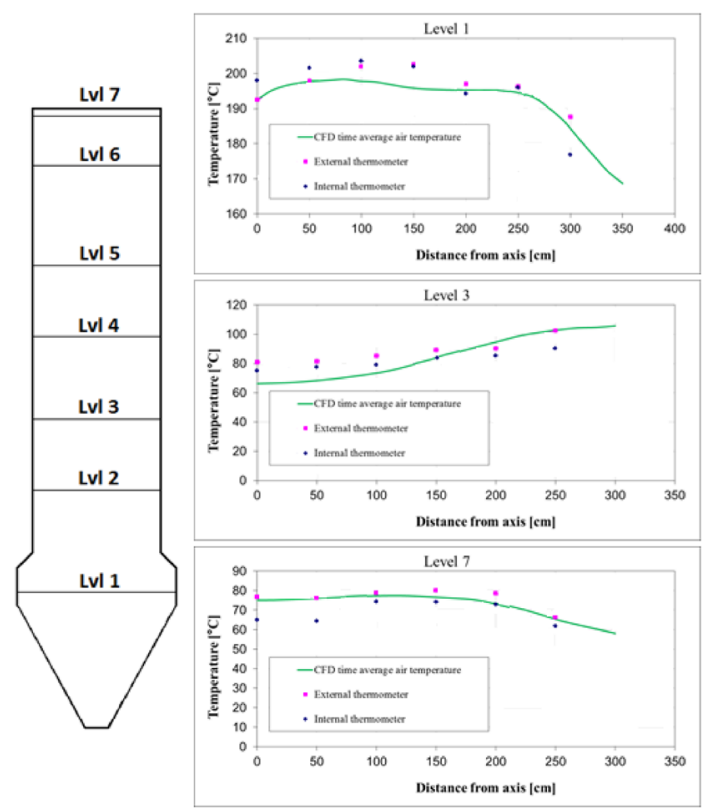

Fig. 17 Radial air temperature profiles (averaged in time), levels, 1, 3 . 7, Jaskulski (2015)

Jaskulski et al. (2015). In this model, particle collisions were divided into three types: collisions of droplets, wet particles and dry particles. The agglomeration correction factor $\gamma$ was proposed to determine a number of the collisions resulted in the agglomeration. For droplets, each collision results in coalescence and correction factor is equal to $1, \gamma=1$. For the particles with moisture content $(X)$ smaller than the critical moisture content $\left(X_{\mathrm{cr}}\right)$, additionally, the condition of critical velocity was checked, Ho and Sommerfeld (2002).

Agglomeration occurs when the relative velocity of colliding particles does not exceed the critical value, then $\gamma=1$. For particles with moisture content lower and relative velocity higher than critical, the agglomeration correction factor is calculated from: $\gamma=X / X_{\mathrm{cr}}$. The probability of agglomeration increases when the dry particle returns to the atomization zone and collides with wet particles.

The mechanism of agglomeration proposed above, Jaskulski et al. (2015) is known, intuitive and accepted. To verify the proposed model of agglomeration, CFD model of counter-current spray drying process was developed and compared with experimental data obtained in a pilot-plant spray drying tower, Piatkowski (2011).

Figure 16 shows a comparison of Sauter mean diameters of particles at different heights of the drying tower obtained from the CFD simulations and experimental data from PDA measurements for different initial process parameters and same distance of the nozzle from air inlets, $4.7 \mathrm{~m}$. Significant increase of the average particle diameters due to agglomeration towards the air inlets is observed. Fine and dry fractions are entrained above the atomizing nozzle but do not agglomerate as the lower moisture content hampers the formation of liquid bridges between the particles during collisions.

In the next step the proposed model of coalescence and

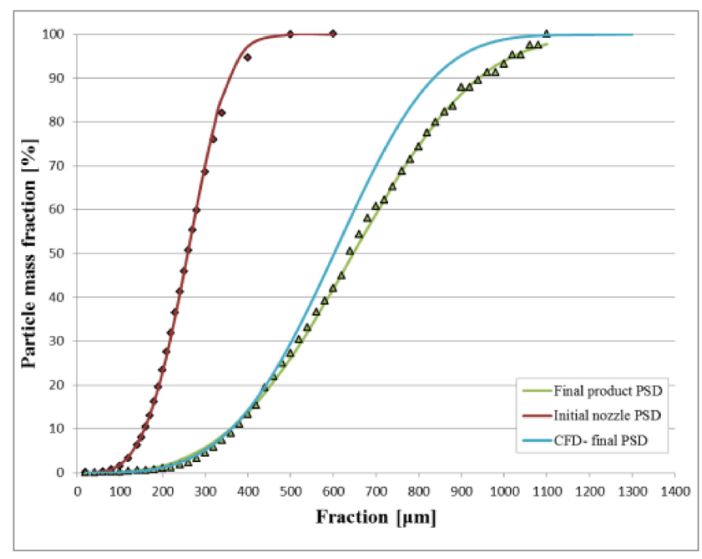

Fig. 18 Comparison of initial and product PSD and diameters from CFD agglomeration model, Jaskulski (2015)

agglomeration was applied for counter-current spray drying in the industrial tower, see Figure 10.

Comparison of measured and calculated time averaged radial air temperature profiles on three tower levels presented in Figure 17, shows good agreement which proves accuracy of CFD model.

The most important, however, was comparison of the PSD of the product measured experimentally with the particle size distribution calculated by the CFD model. The results are shown in Figure 18. The final average particle diameter of the product was $725 \mu \mathrm{m}$ whereas the value obtained in the CFD simulation was $665 \mu \mathrm{m}$. Both curves have a similar shape and overlap for fractions from 20 to $500 \mu \mathrm{m}$, which confirms that the proposed model of agglomeration in spray drying is accurate.

The above own model of particle agglomeration is the first experimentally verified in the literature.

\section{Can We Avoid Modeling of Agglomeration?}

Here we present an expertise made for industrial company regarding constructional changes of hot air inlets in spray tower for production of detergents. The conical surface of the dryer with hot air inlets is the hottest part of the industrial spray drying tower. The area above the hot air inlets is the most threatened with burning of the product. In thermovision pictures, Figure 19, the temperature of single spots around hot air inlets exceeds $160 \div 170^{\circ} \mathrm{C}$ which is close to safety limit.

To reduce the hazard of product burning and/or to increase the dryer throughput of the dryer the surrounding of hot air inlets must be cooled down. The only option to determine and optimize the position of cold air inlets to protect zones threatened with exceeding temperature (ATEX) is application of CFD modeling. Any constructional changes or running of experiments cannot be carried out in industrial towers due to high costs. On the other hand, correct expertise, requires precise CFD model of spray drying which should take into account agglomeration process.

To skip modeling of dispersed phase we elaborated a con- 
cept of a negative heat source (by adding an additional term in N-S equations) reflecting power necessary for evaporation of water during spray drying process, Wawrzyniak et al. (2012b). The probability function to control the distribution of density of power consumption as a function of the distance from the atomizers was determined by trial and error method for industrial tower shown in Figure 10. Many runs were performed to obtain satisfactory agreement between

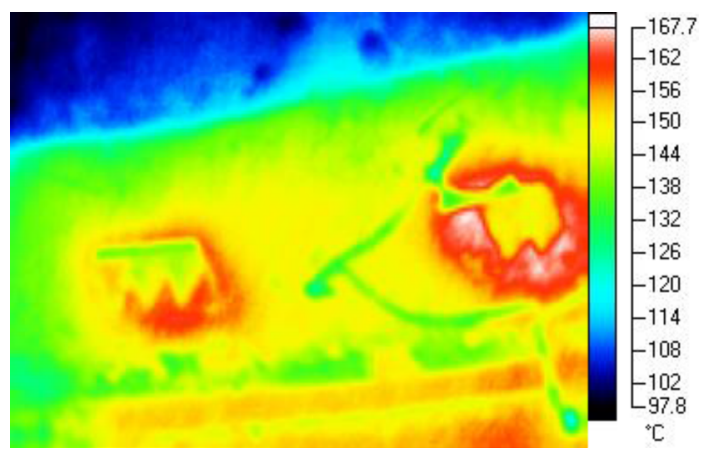

Fig. 19 Picture of hot air inlets (drying process interrupted)

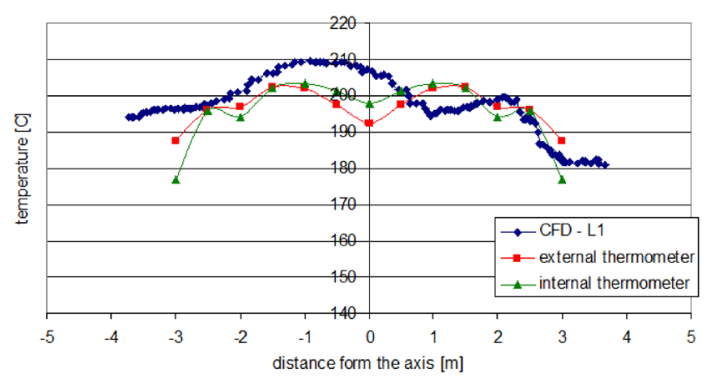

Fig. 20 Example of radial air temperature profiles (averaged in time), Level 1

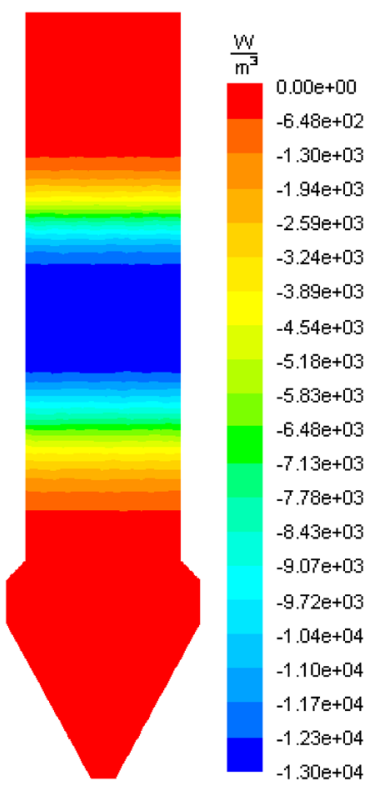

Fig. 21 The area of energy consumption in the industrial tower, final guess, Wawrzyniak et al. (2012b) the theoretical and experimental air temperatures, Figure 20, Wawrzyniak et al. (2012b).

Finally power density distribution function and the area of energy consumption in the industrial tower was determined, Figure 21.

Analysis of the results showed significant unevenness of air velocity distribution inside the ring. The CFD calculations confirm high instability of air flow in the dryer due to geometry of the tower and construction of the air inlet ring.

In the next step CFD calculations were carried out to determine the position of cold air inlets and estimate cooling efficiency of ATEX areas for several configurations. Results of calculation for two selected configurations of cold air inlets: cold air inlets between hot air inlets, cold air inlets below the hot air inlets ring are displayed in Figures 22 and 23.

For all configurations, due to oscillations of gas velocity and temperature in the dryer, dynamic changes of wall temperature were observed which resulted in temporary exceeding of the ATEX temperatures even if time-average wall temperature was below the restricted values.

Analysis of Figures 22 and 23 reveals a big difference in the circumferential cooling of ATEX area for this configuration of cold air inlets. We can see on both, efficient cooling

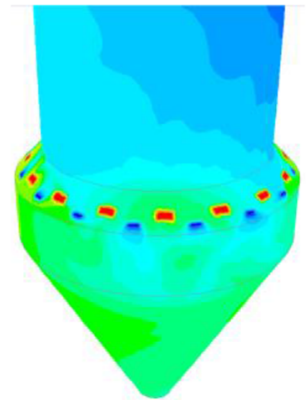

Front view

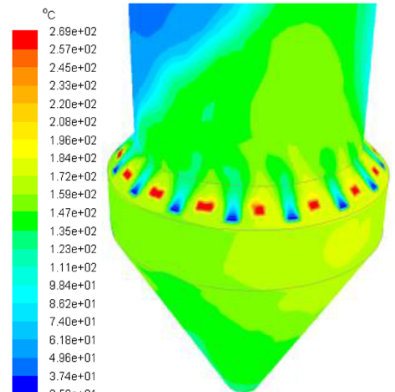

Back view
Fig. 22 Inlet ring wall temperature in the industrial tower for cold air inlets situated between hot air inlets, front view, back view

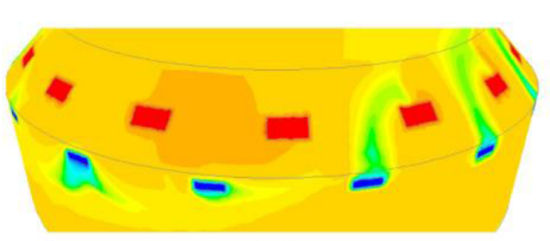

(a)

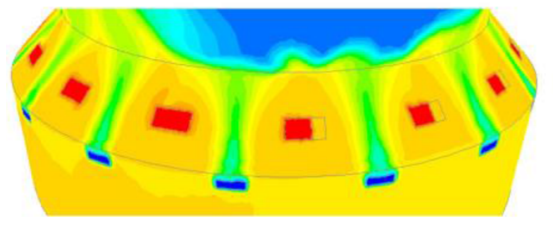

(b)

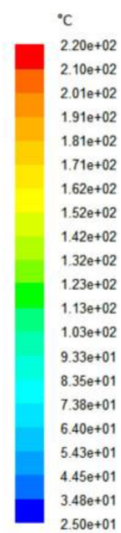

Fig. 23 Inlet ring wall temperature in the industrial tower for cold air inlets situated below the hot air inlets ring (magnification), (a) front view, (b) back view 
of the inlet ring (back view) and, at the same time, no cooling at all (front view).

Analysis of CFD calculations results for all configurations for cooling of the ATEX areas shows that for so unstable hydrodynamics of the continuous phase in the tower full control of wall temperature cannot be achieved. Delivering of cold air circumferentially along the ring by applying air straighteners or nozzles might be a solution for stabile cooling. The idea of negative heat source (hear sink) allowed us to elaborate accurate expertise regarding profitability of constructional changes in the dryer without calculations of agglomeration in counter-current spray tower.

Another approach to avoid modeling of agglomeration was proposed by Montazer-Rahmati and Ghafele-Bashi (2007) who developed simple 2D model of $38 \mathrm{~m}$ tall and $7 \mathrm{~m}$ in diameter countercurrent spray tower for detergentproducing plant. Many serious assumption were employed in the model, e.g., the droplets move parallel to the dryer wall, the diameter of the droplet is constant (agglomeration was not considered) and equal to the dried particle at the bottom of the tower, plug flow regime of hot air inside the spray chamber, etc.

The calculations shown that $6-8 \%$ of the amount of dried product from the bottom is entrained as fines by the hot air leaving the tower top; so neglecting the fines stream in the model equations leads to large errors of the spray drying simulations. The authors claim that results of the model, despite skipping agglomeration process, are in good agreement with industrial data obtained from a detergent-producing plant, calculated and experimental residence times differed with $10 \%$.

\section{Conclusions}

Most of the research works in the industrial spray drying process deal with the control of powder properties, particles agglomeration and residence time, wall deposition and safety issues. All the phenomena are strongly dependent on complex hydrodynamics of flow in the dryer. Results of numerous works on hydrodynamics in spray towers detected transient, three dimensional flow patterns of gas and dispersed phase, oscillations and precession of the main air jet, fluctuations in size of the recirculation zones.

The asymmetries result from the design of inlet and exhaust ducts, the decay of the turbulence kinetic energy, the precession and oscillations of the vortex core and effect of wall friction on swirl decay (due the presence of the deposits). Neglecting of wall roughness in the industrial spray towers might cause a significant over prediction of the tangential velocity and erroneous determination of deposition rate, erosion, particle residence time and the elutriation of the powder.

To reduce wall deposit, the dryer chamber should be well insulated to increase temperature of the particles near the wall.

The key issue in confident scaling up of spray dryers is correct determination of drying kinetics. The Characteristic
Drying Curves (CDC) and the Reaction Engineering Approach (REA) are the methods most often used to determine drying kinetics in industrial dryers. Both techniques require empirical coefficients but many times proved good accuracy in mapping of drying kinetics of the process.

In industrial spray dryers, especially in counter current spray drying process, particles agglomeration controls the final product properties. Many attempts have been made to determine mechanism of agglomeration process, however, none of the particles agglomeration models have been fully validated due to difficulties in measurements in the industrial scale and lack of data on material properties (glass transition temperature or stickiness), tower geometry and operating process parameters.

Two methods for modeling of agglomeration process in industrial spray towers presented in the paper based on arbitrary selected transition functions and full scale agglomeration model which takes into account collisions of droplets and particles and coupling of agglomeration with heat, mass and momentum transfer were validated experimentally in industrial scale.

Accurate description of flow in industrial towers without calculations of agglomeration can be obtained with application of the negative heat source concept.

Continuous progress in modeling of flow hydrodynamics, validation of agglomeration mechanism, development of methods for determination of drying kinetics are important steps towards reliable scaling up of industrial spray drying process.

\section{Acknowledgement}

This is to acknowledge Mariia Sobulska for her help in elaboration of this paper.

\author{
Nomenclature \\ ATEX $=$ atmospheres explosives \\ $\mathrm{CFD}=$ computational fluid dynamics \\ $\mathrm{CDC}=$ characteristic drying curves \\ $\mathrm{DE}=$ dextrose equivalent \\ DKA $=$ drying kinetics analyzer \\ DPM $=$ discrete phase model \\ LDV $=$ laser doppler velocimetry \\ PDA $=$ particle dynamic analysis \\ PSD $=$ particle size distribution \\ REA $=$ reaction engineering approach
}

\section{Literature Cited}

Bayly, A. E., P. Jukes, M. Groombridge and C. McNally; "Airflow Patterns in a Counter-Current Spray Drying Tower-Simulation and Measurement," Proceedings of the 14th International Drying Symposium, vol. B, pp. 775-781, Sao Paulo, Brazil (2004)

Birchal, V. S., L. Huang, A. S. Mujumdar and M. L. Passos; "Spray Dryers: Modeling and Simulation," Dry. Technol., 24, 359-371 (2006)

Chen, X. D. and G. Z. Xie; "Fingerprints of the Drying Behavior of Particulate or thin Layer Food Materials Established Using a Reaction Engineering Model," Food Bioprod. Process., 75, 213-222 (1997)

Chen, X. D.; "Heat-Mass Transfer and Structure Formation during Dry- 
ing of Single Food Droplets,” Dry. Technol., 22, 179-190 (2004)

Chen, X. D.; "The Basics of a Reaction Engineering Approach to Modeling Air-Drying of Small Droplets or Thin-Layer Materials," Dry. Technol., 26, 627-639 (2008)

Fletcher, D. F., B. Guo, D. J. E. Harvie, T. A. G. Langrish, J. J. Nijdam and J. Williams; "What is Important in The Simulation of Spray Dryer Performance And How Do Current CFD Models perform?" Appl. Math. Model., 30, 1281-1292 (2006)

Francia, V., L. Luis Martin, A. E. Bayly and M. J. H. Simmons; "An Experimental Investigation of the Swirling Flow in a Tall-Form Counter Current Spray Dryer," Exp. Therm. Fluid Sci., 65, 52-64 (2015a)

Francia, V., L. Luis Martin, A. E. Bayly and M. J. H. Simmons; "Influence of Wall Friction on Flow Regimes and Scale-Up of Counter-Current Swirl Spray Dryers," Chem. Eng. Sci., 134, 399-413 (2015b)

Gabites, J. R., J. Abrahamson and J. A. Winchester; "Air Flow Patterns in an Industrial Milk Powder Spray Dryer," Chem. Eng. Res. Des., 88, 899-910 (2010)

Gianfrancesco, A., C. Turchiul, D. Flick and E. Dumoulin; "CFD Modeling and Simulation of Maltodextrin Solutions Spray drying to Control Stickiness," Food Bioproc. Techol., 3, 946-955 (2010)

Harvie, D. J. E., T. A. G. Langrish and D. F. Fletcher; "A Computational Fluid Dynamics Study of a Tall-Form Spray Dryer," Food Bioprod. Process., 80, 163-175 (2002)

Hirt, C. W. and B. D. Nichols; "Volume of Fluid (VOF) Method for the Dynamics of Free Boundaries," J. Comput. Phys., 39, 201-225 (1981)

Ho, C. A. and M. Sommerfeld; "Modeling of Micro-Particle Agglomeration in Turbulent Flows," Chem. Eng. Sci., 57, 3073-3084 (2002)

Huntington, D. H.; "The Influence of the Spray Drying Process on Product Properties,” Dry. Technol., 22, 1261-1287 (2004)

Jaskulski, M., P. Wawrzyniak and I. Zbiciński; "CFD Model of Particle Agglomeration in Spray Drying," Dry. Technol., 33, 1971-1980 (2015)

Jaskulski, M.; "CFD Simulations of Particle Agglomeration in CounterCurrent Spray Drying Process," PhD thesis, Lodz University of Technology, Lodz, Poland (2015)

Jin, Y. and X. D. Chen; "A Three-Dimensional Numerical Study of the Gas/Particle Interactions in an Industrial-Scale Spray Dryer for Milk Powder Production,” Dry. Technol., 27, 1018-1027 (2009)

Jin, Y. and X. D. Chen; "A Fundamental Model of Particle Deposition Incorporated in CFD Simulations of an Industrial Milk Spray Dryer," Dry. Technol., 28, 960-971 (2010)

Kievet, F. G. and J. A. M. Kerkhof; "Using Computational Fluid Dynamics to Model Product Quality in Spray Drying: Air Flow, Temperature and Humidity Patterns," Proceedings of the 10th International Drying Symposium, vol. A, pp. 259-266, Krakow, Poland (1996)

Kim, S., D. J. Lee and C. S. Lee; "Modeling of Binary Droplet Collisions for Application to Inter-Impingement Sprays," Int. J. Multiph. Flow, 35, 533-549 (2009)

Langrish, T. A. G. and D. F. Fletcher; "Prospects for the Modelling and Design of Spray Dryers in the 21st Century," Dry. Technol., 21, 197-215 (2003)

Langrish, T. A. G.; "Multi-Scale Mathematical Modelling of Spray Dryers," J. Food Eng., 93, 218-228 (2009)

Li, X. and U. Fritsching; "Analysis and Modeling of Droplet-Droplet Interaction and Particle-Droplet Interaction in Dispersions," Final Report on the Research Grant from the Max Buchner Research Foundation with the Code MBFSt 2902 (2012)

Liou, J. K. and S. Bruin; "An Approximate Method for the Nonlinear
Diffusion Problem with a Power Relation between Diffusion Coefficient and Concentration. 1. Computation of Desorption Times.", Int. J. Heat Mass Transfer, 25, 1209-1229 (1982)

Masters, K.; "Scale-Up of Spray Dryers," Dry. Technol., 12, 235-257 (1994)

Masters, K.; Spray Drying Handbook, George Godwin, London, U.K. (1985)

Mezhericher, M., A. Levy and I. Borde; "Theoretical Drying Model of Single Droplets Containing Insoluble or Dissolved Solids," Dry. Technol., 25, 1025-1032 (2007)

Montazer-Rahmati, M. M. and S. H. Ghafele-Bashi; "Improved Differential Modeling and Performance Simulation of Slurry Spray Dryers as Verified by Industrial Data," Dry. Technol., 25, 1451-1462 (2007)

Nijdam, J. J., B. Guo, D. F. Fletcher and T. A. G. Langrish; "Challenges of Simulating Droplet Coalescence within a Spray," Dry. Technol., 22, 1463-1488 (2004)

Oakley, D. E.; "Scale-Up of Spray Dryers with the Aid of Computational Fluid Dynamics," Dry. Technol., 12, 217-233 (1994)

Orme, M.; "Experiments on Droplet Collision, Bounce, Coalescence and Disruption," Pror. Energy Combust. Sci., 23, 65-79 (1997)

Percy, S. R.; "Improvement in Drying and Concentrating Liquid Substances by Atomizing," US Patent, 125,406 (1872)

Piatkowski, M.; "Drying Kinetics in Counter-Current Spray Drying Process," PhD thesis, Lodz University of Technology, Lodz, Poland (2011)

Rahse, W. and O. Dicoi; Spray Drying in the Detergent Industry, Spray Drying '01 and Related Processes, University of Technology, pp. 83-87, Dortmund, Germany (2001)

Straatsma, J., G. Van Houwelingen, A. E. Steenbergen and P. De Jong; "Spray Drying of Food Products. 1. Simulation Model," J. Food Eng., 42, 67-72 (1999)

Taskiran, O. O. and M. Ergeneman; “Trajectory Based Droplet Collision Model for Spray Modeling," Fuel, 115, 896-900 (2014)

Taylor, T.; "Concurrent and Countercurrent Spray Drying and Particle Morphology," Proceedings of 12th International Drying Symposium, Paper No. 9, Noordwijkerhout, The Netherlands (2000)

Tsotsas, E. and A. S. Mujumdar; Modern Drying Technology, vol. 1: Computational Tools at Different Scales., 1st ed., WILEY-VCH, Darmstadt, Germany (2007)

Ullum, T., J. Sloth, A. Brask and M. Wahlberg; "Predicting Spray Dryer Deposits by CFD and an Empirical Drying Model," Dry. Technol., 28, 723-729 (2010)

Wawrzyniak, P., M. Podyma, I. Zbiciński, Z. Bartczak and J. Rabaeva; "Modeling of Air Flow in an Industrial Countercurrent SprayDrying Tower," Dry. Technol., 30, 217-224 (2012a)

Wawrzyniak, P., M. Podyma, I. Zbiciński, Z. Bartczak, A. Polańczyk and J. Rabaeva; "Model of Heat and Mass Transfer in an Industrial Counter-Current Spray-Drying Tower," Dry. Technol., 30, 12741282 (2012b)

Wawrzyniak, P., M. Jaskulski, I. Zbiciński and M. Podyma; "CFD Modelling of Moisture Evaporation in an Industrial Dispersed System," Adv. Powder Technol., 28, 167-176 (2017)

Woo, M. W., W. R. W. Daud, A. S. Mujumdar, Z. H. Wu, M. Z. Meor Talib and S. M. Tasirin; "CFD Evaluation of Droplet Drying Models in a Spray Dryer Fitted with Rotary Atomizer," Dry. Technol., 26, 1180-1198 (2008)

Woo, M. W., L. M. Che, W. R. W. Daud, A. S. Mujumdar and X. D. Chen; "Highly Swirling Transient Flows in Spray Dryers and Consequent Effect on Modeling of Particle Deposition," Chem. Eng. Res. Des., 90, 336-345 (2012) 